Volume 15 Issue 4 Year: 2018

\title{
Effects on level of their nutrition knowledge of nutrition training given to adult prisoners in Amasya, Turkey ${ }^{1}$
}

\author{
Mukaddes Örs ${ }^{2}$
}

\begin{abstract}
Purpose: The objective of the present study is to determine the impacts on their nutritional knowledge of the nutrition training provided to the adult male prisoners in the Closed Prison.

Method and material: Experimental, which is a quantitative research method, has been used in the present study. Data were derived from pretest, posttest and monitoring test questionnaires completed by prisoners. The population for the study consisted of 504 adult male prisoners from the Amasya Type E Closed Prison Institution. 216 adult male prisoners were selected through voluntary selection. The 216 adult male prisoners were randomly divided into four groups, control (54), education (54), brochure (54) and education+brochure (54). Research data were collected with the help of a survey form using the face-to-face interview technique. Thirtyone multiple-choice questions were on the questionnaire. Statistical software was used to analyze change scores for pre-, posttest and monitoring test measures with the independent sample t test and single direction variance analysis (ANOVA) tests.
\end{abstract}

Results: Analyzing the impact of education on nutritional knowledge, it has been found that the average score in the education group in the pretest measurement was 6.22 and the average score in the posttest measurement was 21.34. This difference between the scores was significant $(\mathrm{p}<0.05)$. In the "brochure+education" group, a significant difference was found between the posttest scores and monitoring test scores $(\mathrm{p}<0.05)$.

Conclusion: The results of the study show that inmate participants could benefit from nutrition education and suggest that further investigations should be performed in a larger study population.

Keywords: Prison; prisoners; adult education; life-long learning, nutrition education

\section{Introduction}

A Type E Closed Prison includes each type of crime group in Turkey. Part of the Amasya Type E Closed Prison, which has been in service since 1969, was transformed into a HighSecurity Closed Prison. Its total capacity for convicts and detainees is 550. Out of this 550-person capacity, 504 are adult males. In addition, there are two rooms each for 10 children younger than 18 years of age and there are two rooms each for 15 adult females. There are no surrounding walls in the prison, but there is one canteen, a tea house, a bookbinding workshop, a tailor workshop, a shoemaking workshop and a photographer's studio operating under the Prison Workshop (The Turkish Republic Ministry of Justice, 2015).

${ }^{1} \mathrm{~A}$ part of this study was orally presented at the $3^{\text {rd }}$ World Conference on Health Sciences in Izmir (28-30 April 2016). ${ }^{2}$ Asst. Prof. Dr., University of Amasya, Faculty of Health Sciences, Nutrition and Dietetics Department, mukaddesors@hotmail.com 
Örs, M. (2018). Effects on level of their nutrition knowledge of nutrition training given to adult prisoners in Amasya, Turkey. Journal of Human Sciences, 15(4), 2592-2601. doi:10.14687/ihs.v15i4.5015

In many countries worldwide, insufficient, unbalanced nutrition is becoming a serious problem. The prevalence of obesity is associated with unbalanced nutrition, and chronic diseases (cardiovascular diseases, cancer, diabetes, osteoporosis, etc.) associated with nutrition are continuously increasing. In a cross-sectional community-based study, the prevalence of obesity among the individuals over 20 years old was found to be $22.3 \%$ (12.9\% among men) (TBSA, 2015).

Prisoners tend to have bad physical, mental and social health than the general population (Loring and Robertson, 2015). The concept of the prison as a setting for health promotion has been nationally and internationally recognized (Hayton, Van den Bergh, \& Moller, 2010). A whole-prison approach to promoting health draws on key component, such as disease prevention, health education and other health promotion initiatives that address the health needs assessed within each prison (World Health Organization, 1986).

All prisoners need assistance to deal with and control the impact of prison. All prisoners are perhaps need support in adopting healthy behaviors, such as a balanced diet (Baybutt, Acin, Hayton, \& Dooris, 2015).

The World Health Organization stated that the prevalence of chronic diseases in developing countries can be decreased by changes in diet and lifestyle (World Health Organization, 2015). Food and Nutrition Education is a key tool in preventing, promoting and treating nutrition disorders and chronic diseases (Hernando, Minchón, Zamorano, \& Domínguez, 2009). To prevent chronic diseases, healthy nutrition practices should be included in public education approaches.

Previous research has shown an increase in knowledge after nutrition education intervention among prisoners in prisons; a experimental study conducted on women in prison by Dang (2012) nutrition education program focused on promoting better health and prevention of chronic diseases. The evaluation design was a one-group quasi-experimental design with pre- and post-test measures. Identical pre- and post-tests were administered before and after the intervention. After four nutrition education sessions, post-tests revealed an overall increase in knowledge, and self-efficacy scores, and decrease in perceived barrier scores towards fruit and vegetable consumption. In an other study, evaluated of Effectiveness of a Voluntary Nutrition Education Workshop in a State Prison, analysis of changes in health risk appraisal responses relating to nutrition, general health, and social ties found that a significantly greater proportion of participants than controls reported improved nutrition. This study suggests that inmate participants and the penal system may benefit from nutrition workshops (Curd, Ohlmann, \& Bush, 2013). Also, an intervention program conducted by Sebelia and Greene (2007) the intervention consisted of 4 stage of change tailored newsletters mailed weekly promoting consumption of fruits and vegetables. Prisoners were assessed pre and post intervention; stage was re-assessed after the first 2 newsletters to confirm or revise tailoring. All assessments were conducted by trained interviewers over the telephone. This intervention has a positive short-term impact on behavior, motivational readiness to consume 5 cups of fruit and vegetable/day, and self-efficacy in this vulnerable population.

For individuals to have healthy eating habits, correct food preferences and a healthy lifestyle, they need to have an adequate level of knowledge on nutrition. Correct knowledge of nutrition can be attained with nutrition education. Nutrition education programs have been stated to have a effect on the knowledge of nutrition (Steafleu, Staveren, Graaf, Burema, \& Hautvast , 1996). Örs and Kalkan (2017) evaluated that level of nutriton knowledge male prisoners' in prison. In this study, approximately $76 \%$ of the prisoners stated that they have not received nutrition related training in Turkey (Örs, Kalkan, 2016).

Being healthy and protected from disease is as important for prisoners as for all other individuals. A country should protect and improve the health of prisoners under its protection. The tasks related to the protection and improvement of health are clearly stated in the national 
Örs, M. (2018). Effects on level of their nutrition knowledge of nutrition training given to adult prisoners in Amasya, Turkey. Journal of Human Sciences, 15(4), 2592-2601. doi:10.14687/ihs.v15i4.5015

legislation concerning the General Directorate of Prisons operating under the Ministry of Justice in Turkey (The Turkish Republic Ministry of Justice, 2015).

However, because no study on nutrition training of prisoners in prisons is available in the literature in Turkey and there are limited studies in the worldwide literature, there is a need for studies on this subject. In this regard, the present study is important because it is both empirical and addresses the need for knowledge in this field. The objective of the present study is to determine the impacts on their nutritional knowledge of the nutrition training provided to adult male prisoners in the Amasya Type E Closed Prison.

\section{Research Methodology}

\subsection{Type of study}

Experimental, which is a quantitative research method, has been used in the present study. This study was designed as an experimental study (Büyüköztürk, 2010; Arıkan, 2011; Ekiz, 2013). An experimental study was conducted that compared the following four groups of prisoners: experimental group [education ( $n=54)$, education + brochure $(n=54)$, brochure $(n=54)$ ] and control group ( $\mathrm{n}=54)$. Pretests-posttest, monitoring test (delayed post-posttest) and control group design were conducted between April 1 and August 20, 2015. Data were derived from pretest, posttest and monitoring test (delayed post-posttest) questionnaires completed by prisoners. The investigator was responsible for explaining the details to the prisoners to ensure that they understood all items and for examining the completeness of recycled questionnaires. The nutritional education was provided for education and education + brochure groups but not for the other groups. Nutritional education were provided orally by the researcher for 108 prisoners who were selected for training and education+brochure groups as two course hours per week for two weeks. Education and nutrition information brochures included the description of nutritional elements and the food groups, habit of drinking, food preparation and cooking rules, and the changes should be made in nutritional habits. Nutrition information brochures were also prepared by the researcher. The education+ brochure and brochure groups was distributed nutrition information brochures. Pretest data on nutrition knowledge for all of groups was collected first at the same time. Prisoners in control group did not receive any intervention from the researchers.

The prisoners were asked 31 questions in order to determine nutritional knowledge. These questions were asked to the prisoner once before the education (pretest), (1), once after the education (posttest) (2), and once three months after the education (delayed post-posttest or monitoring test) (3), totally three times. The right answers were evaluated as " 1 " point and the wrong answers were evaluated as " 0 ". The total point is 31 , if all questions were replied correctly.

\subsection{Population and sample selection}

The population for the study consisted of 504 adult male prisoners from the Amasya Type E Closed Prison Institution. When the population size was considered for 5\% deviation and for $95 \%$ confidence interval, it was observed that 216 people can represent a sub-population of 504 adult prisoners (Balc1, 2005; Büyüköztürk, 2010; Arıkan, 2011). Therefore, 216 adult male prisoners were selected through voluntary selection. The 216 adult male prisoners were randomly divided into four groups (Büyüköztürk, 2010; Arrkan, 2011; Ekiz, 2013); control (54), education (54), brochure (54) and education+brochure (54). In the final survey, four participants in the control group, in the education and education + brochure groups did not complete the questionnaire. Two hundred and sixteen prisoners started the program, and 204 finished the program.

\subsection{Data collection tools}

Questionnaires were prepared by the researcher based on previous studies (Dang, 2012; Curd, Ohlmann, \& Bush, 2013; Sebelia, Greene, 2007; Khattak, Ullah, Abbas, Paracha, Parvez, \& Khan, 2008; Parmenter, \& Wardle, 1999). A two-part questionnaire was developed to collect data. Part one contained demographic questions, such as the gender, age, occupation, duration in the 
Örs, M. (2018). Effects on level of their nutrition knowledge of nutrition training given to adult prisoners in Amasya, Turkey. Journal of Human Sciences, 15(4), 2592-2601. doi:10.14687/jhs.v15i4.5015

prison, any training in the prison, the training subject and education status. Part two contained 31 questions pertaining to general nutrition knowledge. Questions were measured using a multiple choice format. Research data were collected with the help of a survey form using the face-to-face interview technique.

The questionnaire was revised and improved by experts in the field in terms of face validity (content validity and construct validity) (Balc1, 2005). A panel of experts (two nutrition education specialists and three faculty members at a different University) reviewed the questionnaire for face validity. Through three rounds of consultations and feedbacks, an initial pool of 31 items was derived. The content validity of the questionnaire was evaluated by the experts. Then, a pilot test was conducted with 93 prisoners (from another prison) that were not included in the study to estimate the instrument reliability. After the pilot test, The Kuder Richardson Formula 20 Reliability Coefficient (KR-20) was obtained as 0.76. All parts of the questionnaire had acceptable reliability. All the parts of the questionnaire had acceptable reliability.

This questionnaire included demographic information and 31 items of knowledge (singleanswer questions), Examples of items are shown in Table 1.

\begin{tabular}{|c|c|c|}
\hline Dimension & Issue & Type of Items \\
\hline Knowledge & Nutriton & $\begin{array}{c}\text { Single answer You need vitamins for eye health what is it? } \\
\text { (1) Vitamin D (2) Vitamin A (3) Vitamin E (4) } \\
\text { Vitamin C }\end{array}$ \\
\hline Knowledge & Nutrition & $\begin{array}{l}\text { Single answer Which of the following food contains most } \\
\text { vitamin C? (1) Liver (2) Orange (3) Potato (4) } \\
\text { Cauliflower }\end{array}$ \\
\hline Knowledge & Nutrition & 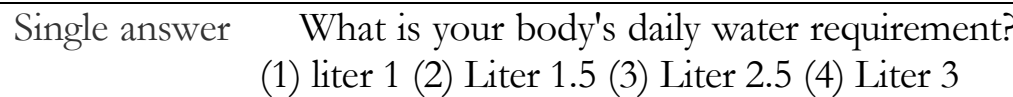 \\
\hline Knowledge & Nutrition & $\begin{array}{l}\text { Single answer Which of the following food contains most } \\
\text { fiber? (1) molasses (2)Apple (3) Orange Juice } \\
\text { (4) haricot bean }\end{array}$ \\
\hline
\end{tabular}

\subsection{Limitations}

In most of the investigations performed in prisons, there are necessary bureaucratic procedures because the field being studied is a sensitive area for the interviewers, administration and Ministry of Justice, which may complicate the study procedures.

There were no restrictions on the study sample; participants consisted of men of every crime type, over the age of 18 years, with different punishment periods. Since participation was voluntary, the sample size can be limited by prisoners who refuse to participate. In this study, two hundred and sixteen prisoners started the program, while 204 finished the program.

\subsection{Research ethics}

Permission of the institution was obtained before the study and oral approval of the prisoners and convicted obtained after explaining the purpose of the study. Then, the information regarding the content of the study was given to all the prisoners and convicted. In addition, the fact that personal information would not be disclosed to third parties and compliance with the principle of "Privacy and Protection of Privacy" ensured.

\subsection{Evaluation of Data}

Statistical analysis of the data was performed with Data were entered and analyzed using a Statistical Package for Social Sciences (SPSS) version 17.0 for windows vista 2007; Chicago, II, and the figures and percentages were evaluated using the independent sample $t$ test and single direction variance analysis (ANOVA) test. 


\section{Results}

When the demographic features of the prisoners are examined, it can be seen that all participants $100 \%$ are males, $24.5 \%$ are $41-50$ years of age, $48.5 \%$ are self-employed, approximately $81.4 \%$ had been in the prison for 5 years or less, $75.5 \%$ did not receive any training while they were in prison, $85.4 \%$ of those who received education studied health, $47.5 \%$ were primary school graduates, $30.9 \%$ were secondary school graduates, $12.3 \%$ were high school graduates and $5.9 \%$ were university graduates.

Table 2. Descriptive Statistics and Demographic Characteristics of Prisoners

\begin{tabular}{lccc}
\hline Characteristics & Group & f & \% \\
\hline Gender & Male & 204 & 100.0 \\
Age & $25 \leq$ & 46 & 22.5 \\
& $26-30$ & 48 & 23.5 \\
& $31-40$ & 49 & 24.0 \\
Occupation & $41-50$ & 50 & 24.5 \\
& 51 or over & 11 & 5.4 \\
& Public servant & 6 & 2.9 \\
& Worker & 59 & 28.9 \\
Duration in the prison & Self employed & 99 & 48.5 \\
& Retired & 17 & 8.3 \\
Any education in the prison & Not working & 20 & 9.8 \\
Subject studied & 1 year or less & 84 & 41.2 \\
& $2-5$ years & 82 & 40.2 \\
Education status & 6-10 years & 30 & 14.7 \\
& 10 years or over & 4 & 2.0 \\
& Yes & 48 & 23.5 \\
& No & 154 & 75.5 \\
& About health & 7 & 14.6 \\
& Not health & 41 & 85.4 \\
& Illiterate & 4 & 2.0 \\
& Literate & 3 & 1.5 \\
& Primary school & 97 & 47.5 \\
& Secondary school & 63 & 30.9 \\
& High school & 25 & 12.3 \\
& University & 12 & 5.9 \\
\hline
\end{tabular}

When Table 3 is examined, it can be seen that the lowest average scores (5.80) were obtained in the pretests of the "brochure+education" group, while the highest average scores (23.4) were obtained in the posttests of the "brochure+education" group. Additionally, each educational session increased the averages. All groups, except the control group, had higher mean posttests compared to pretests. In an assessment of the scores of the prisoners concerning nutrition knowledge, the average scores of the control group were the lowest (7.94). 
Örs, M. (2018). Effects on level of their nutrition knowledge of nutrition training given to adult prisoners in Amasya, Turkey. Journal of Human Sciences, 15(4), 2592-2601. doi:10.14687/jhs.v15i4.5015

Table 3. The Descriptive Statistics Related to the Prisoner Scores in the Pretests, Posttests and Delayed Post-Posttest (Monitoring Tests) on Their Nutrition Knowledge

\begin{tabular}{lcccccc}
\hline Group & Test & $\mathbf{n}$ & Min. & Max. & $\bar{X}$ & SS \\
\hline Brochure & Pre-test & 54 & 0.00 & 21.00 & 6.56 & 4.77 \\
Brochure & Post-test & 54 & 1.00 & 25.00 & 8.44 & 6.36 \\
Brochure & Monitoring & 50 & 1.00 & 27.00 & 9.78 & 6.62 \\
Education & Pre-test & 50 & 0.00 & 24.00 & 6.22 & 5.49 \\
Education & Post-test & 50 & 7.00 & 29.00 & 21.34 & 8.92 \\
Education & Monitoring & 50 & 0.00 & 31.00 & 19.96 & 5.10 \\
Brochure+education & Pretest & 50 & 0.00 & 18.00 & 5.80 & 4.55 \\
Brochure+education & Posttest & 50 & 1.00 & 31.00 & 23.04 & 7.72 \\
Brochure+education & Monitoring & 50 & 0.00 & 29.00 & 16.04 & 6.30 \\
Control & & 50 & 0.00 & 18.00 & 7.94 & 4.58 \\
\hline
\end{tabular}

As can be seen in Table 4, there was a significant increase in scores after nutritional education for prisoners. The mean nutritional knowledge scores of the prisoners prior to education was 6.22 , which increased to 21.34 following education. The lowest scores (5.80) in the pretest was for the "brochure +education" group, and the highest scores (23.04) in the posttest was for to the "brochure + education" group, which was followed by the "education" (21.34) and "brochure" (8.44) groups.

In Table 4, only in the group for which education was provided in brochures were there no significant differences between the pretest and posttest scores $(p>0.05)$. Significant differences were found between the pretest and posttest scores in the group for which only "education" was provided and between the scores in the group for which "brochure+education" was provided $(\mathrm{p}<0.05)$. In these two groups, the posttest scores were higher than the pretest scores.

Table 4.The t-Test Results of the Nutrition Knowledge Pretest-Posttest Points of Prisoners

\begin{tabular}{lccccccc}
\hline Group & Test & $\mathbf{n}$ & $\overline{\mathbf{X}}$ & $\mathbf{S S}$ & $\mathbf{t}$ & $\mathbf{S d}$ & $\mathbf{p}$ \\
\hline Brochure & Pretest & 54 & 6.56 & 4.77 & -1.55 & 53 & .126 \\
& Posttest & 54 & 8.44 & 6.36 & & & \\
Education & Pretest & 50 & 6.22 & 5.49 & -13.75 & 49 & .000 \\
\multirow{3}{*}{ Brochure+education } & Posttest & 50 & 21.34 & 5.10 & & & \\
& Pretest & 50 & 5.80 & 4.55 & -13.01 & 49 & .000 \\
& Posttest & 50 & 23.04 & 7.72 & & & \\
\hline
\end{tabular}

As can be seen in Table 5, the subjects with the highest nutritional knowledge score on the posttest belonged to the "brochure + education" group (23.04), which was followed by the "education" (21.34) and "brochure" (8.44) groups. In the Monitoring test, the mean scores of nutritional knowledge seem to have decreased in all groups. These results suggest that the nutritional education process should be ongoing with reeducation at certain intervals for it to have a lasting effect. The highest nutritional information scrores increase occurred in the "brochure + education" group.

Additionally, in Table 5, the scores somewhat increased in the posttest -monitoring tests in the brochure group; however, there was no significant difference between the posttest and monitoring test scores $(\mathrm{p}>0.05)$. In the "brochure+education" group, a significant difference was 
Örs, M. (2018). Effects on level of their nutrition knowledge of nutrition training given to adult prisoners in Amasya, Turkey. Journal of Human Sciences, 15(4), 2592-2601. doi:10.14687/jhs.v15i4.5015

found between the posttest and monitoring test scores $(\mathrm{p}<0.05)$. The monitoring test scores were significantly lower than the posttest scores.

Table 5. The t-Test Results of the Nutrition Education, and Posttest-Delayed Post-Posttest (Monitoring) Test Points of Prisoners

\begin{tabular}{lccccccc}
\hline Group & Test & $\mathbf{n}$ & $\overline{\mathbf{X}}$ & $\mathbf{S S}$ & $\mathbf{t}$ & $\mathbf{s d}$ & $\mathbf{p}$ \\
\hline Brochure & Posttest & 54 & 8.44 & 6.52 & -0.82 & 49 & .417 \\
& Monitoring & 50 & 9.78 & 6.62 & & & \\
Education & Posttest & 50 & 21.34 & 8.92 & -0.92 & 49 & .364 \\
\multirow{4}{*}{ Brochure+education } & Monitoring & 50 & 19.96 & 5.10 & & & \\
& Posttest & 50 & 23.04 & 7.72 & 5.67 & 49 & .000 \\
& Monitoring & 50 & 16.04 & 6.30 & & & \\
\hline
\end{tabular}

In Table 6, it can be seen that the posttest scores belonging to the group that had been given "brochure+education" were significantly higher than the average scores for the "education" and control groups $(\mathrm{p}<0.05)$. The education provided to the "education" and "brochure+education" groups was more effective when compared to the education provided to the "brochure" and "control" groups. A significant difference was found between the brochure group posttest points and the brochure+education group posttest points $(\mathrm{p}<0.05)$. The brochure group posttest points (8.44) are significantly lower than the brochure + education posttest points (23.04).

Table 6. The ANOVA Results of the Posttest Points of Prisoners

\begin{tabular}{lccccccc}
\hline Test & Group & $\mathbf{n}$ & $\overline{\mathbf{X}}$ & $\mathbf{S S}$ & $\mathbf{F}$ & $\mathbf{p}$ & $\begin{array}{c}\text { Significant } \\
\text { Difference }\end{array}$ \\
\hline Posttest & Brochure & 54 & 8.44 & 6.36 & 83.78 & .000 & $1-2$ \\
& Education & 50 & 21.34 & 8.92 & & & $1-3$ \\
& Brochure+education & 50 & 23.04 & 7.72 & & & $2-4$ \\
& Control & 50 & 7.94 & 4.58 & & & $3-4$ \\
\hline
\end{tabular}

\section{Discussion}

The nutrition knowledge scores for the prisoners participating in nutrition education were significantly increased at posttest and monitoring test compared to prisoners in the control group.

When replies to the questions on nutritional education were examined in full, it was discovered that the success rate increased among prisoners in the Amasya Type E Closed Prison at the end of the education. The highest success rate was observed in the "brochure+education" group, which indicates that the combination of both verbal and visual education increases the effectiveness of education when they are provided together. Additionally, there was a decrease in the success rate of prisoners in the monitoring test provided 3 months after the education session. This indicates that the education should be periodically renewed.

Analyzing the effect of education on nutritional knowledge, it was found that the average scores of the education group in the pretest measurement was 6.22 and the posttest measurement average score was 21.34; this difference between the scores was significant $(p<0.05)$. Nutritional education has further importance in diseases that last a lifetime, such as diabetes. The average score of the brochure+education group in the pretest measurement was 5.80 and the posttest measurement average score was 23.04; this difference between the scores was significant 
Örs, M. (2018). Effects on level of their nutrition knowledge of nutrition training given to adult prisoners in Amasya, Turkey. Journal of Human Sciences, 15(4), 2592-2601. doi:10.14687/ihs.v15i4.5015

$(\mathrm{p}<0.05)$. Many studies on the influence of education on nutritional knowledge have demonstrated that education has helped overcome inadequate and unbalanced nutrition.

Similar findings have been reported in related papers, although some might have methodological differences with respect to statistical techniques. An experimental study was conducted on women in prison by Dang (2012) which involved a nutrition education program focused on promoting better health and prevention of chronic diseases by increasing fruit and vegetable intake and healthy eating on a limited budget. The Hope for Health Nutrition Education Program occurred in four weekly sessions at Brigid's Hope. The evaluation design was a single-group, quasi-experimental design with pretest and posttest measures. After four nutrition education sessions, posttests revealed an overall increase in knowledge, skills, and selfefficacy scores as well as a decrease in perceived barrier scores towards fruit and vegetable consumption (Dang, 2012). Another study evaluated the Effectiveness of a Voluntary Nutrition Education Workshop in a State Prison, analyzing changes in the health risk appraisal responses related to nutrition, general health, and social ties, and found that a significantly greater proportion of participants than controls reported improved nutrition practices $(23.5 \%$ vs. $3.2 \%$, $\mathrm{p}=.047)$. This study suggests that inmate participants and the penal system may benefit from nutrition workshops (Curd, Ohlmann, \& Bush, 2013). Additionally, Sebelia and Grene (2007) conducted an intervention program. The intervention consisted of 4 stages of change tailored newsletters that were mailed weekly and promoted the consumption of fruits and vegetables. Prisoners were assessed before and after intervention; the stage was re-assessed after the first 2 newsletters to confirm or revise tailoring. All assessments were conducted by trained interviewers over the telephone. This intervention has a positive short-term impact on behavior, motivational readiness to consume 5 cups of fruits and vegetables/day, and self-efficacy in this vulnerable population (Sebelia and Grene, 2007).

As in other studies, the present study suggests that the level of nutritional knowledge significantly increases $(\mathrm{p}<0.05)$ among the individuals with nutritional education. In their study on the nutrition education needs of women who are released from prison. Decker and Dharod (2005) evaluated that the level of nutrition knowledge among participants was different. Nutrition knowledge or interest was higher in women whose family had a history of chronic diseases, such as diabetes, high blood pressure or a medical condition such as PKU (Phenylketonuria).

At the end of the nutritional education provided to prisoners in the Amasya Type $\mathrm{E}$ Closed Prison, an increase was observed in the level of nutritional knowledge among these prisoners. Therefore, it is suggested that additional studies evaluating the nutritional attitudes and behaviors of prisoners in prisons be performed.

The results of this study suggest that education had a positive effect on nutrition knowledge. This finding is expected. Additionally, for the information to have a lasting effect, the training needs to be intermittently repeated. Based on these results, individuals and society need to gain more awareness of nutrition. With nutrition education, people can become more productive, healthy individuals who eat in an adequate and balanced way, which will also minimize the healthcare costs. To eat in an adequate and balanced way, people need to have the relevant knowledge on nutrition, which can be achieved with training. By including nutrition in the educational curriculum used in prisons, prisoners should be encouraged to engage in more healthy living. In providing prisoners with this education, it is expected that they can consume the nutrients needed by the body at all stages of life in an adequate and balanced way; they will replace poor nutritional behaviors and habits with healthy behaviors; nutritional disorders resulting from inadequate, unbalanced feeding will be prevented; and they will begin to prefer food and drinks with high nutritional value over fast food products with empty calories and carbonated drinks. 
Örs, M. (2018). Effects on level of their nutrition knowledge of nutrition training given to adult prisoners in Amasya, Turkey. Journal of Human Sciences, 15(4), 2592-2601. doi:10.14687/ihs.v15i4.5015

In line with the principle that "nutrition is the essence of health", there is a need for studies to increase the level of knowledge of nutrition throughout the population. To support these studies, nutrition education should be promoted with mass media, such as the radio, television and newspapers. The present study, which was conducted to determine the effectiveness of the nutritional education provided to prisoners in correcting nutritional habits, is important in terms of setting a database for similar studies that can be conducted in the future.

This study concludes that inmate participants could benefit from nutrition education and suggests that further investigations should be performed in a larger study population.

\section{References}

Arıkan, R. (2011). Arastırma yöntem ve teknikleri. 1. Baskı. Ankara: Nobel Akademik Yayıncilik Eğitim Danışmanlık Tic. Ltd.Şti

Balc1 A. (2005). Sosyal bilimlerde arastırma. 5. Bask1. Ankara: Pegem A yayınc1lik.

Baybutt, M., Acin, E., Hayton, P., Dooris, M. (2014).Promoting health in prisons: A settings approach. http://www.euro.who.int/_data/assets/pdf_file/0005/249188/Prisons-an Health.pdf?ua=1. Accessed September 12015.

Büyüköztürk, Ş. (2010). Bilimsel araștırma yöntemleri. 5. Bask1. Anklara: pegem Akademi

Curd, P., Ohlmann, K., Bush, H. (2013). Effectiveness of a voluntary nutrition education workshop in a State Prison. Journal of Correctional Health Care, 19(2), Avaliable at:http://journals.sagepub.com/doi/pdf/10.1177/1078345812474645.Accessed March 12, 2017.

Dang, F. (2012). Effectiveness of a nutrition education program for women in a residential program after incarceration. Texas Medical Center Dissertations.

D'Asaro, B., Groesbeck, C., Nigro, A. (1975). Diet-vitamin program for jail inmates, Orthomolecular Psychratry, 4(3):212-222. Avaliable at: http://citeseerx.ist.psu.edu/viewdoc/download?doi=10.1.1.597.2707\&rep=rep1\&type $=p d$ f. Accessed March 12,2017.

Decker, J., Dharod, J. (2005). Nutrition education needs of women being released from prison Maine Reentry Nutrition Initiative. Available at: https://snaped.fns.usda.gov/snap//resourcefinder/WomenReleasedFromPrison.pdf. Accessed November 15, 2015.

Ekiz, D. (2013). Bilimsel araștırma yöntemleri. 3. Baskı. Ankara: Anı Yayıncllk.

de Viggiani, N. (2007). Unhealthy prisons: exploring structural determinants of prison health. Sociol Health Illn, 29:115-135.

de Viggiani, N. (2012). Creating a healthy prison: Developing a system wide approach to public health within an English prison. Prison Ser J. 202:12-19.

Hayton, P., van den Bergh, B., Moller, L. (2010). Health protection in prisons", the madrid recommendation. Public Health, 124(11): 635-636.

Hernando, Minchón A., Zamorano, Domínguez J.A. \& Delgado Gil, Y. (2009). Health education in prisons: assessment of an experience with diabetics. Rev Esp Sanid Penit, 11: 73-79.

Khattak, I. A., Ullah, N., Abbas, M., Paracha, Parvez I., Khan, S. (2008). Prisoners women and children - from nutritional perspective. Sarbad J. Agric, 24(1): 123-128.

Loring, B., Robertson, A. (2014). Obesity and inequities. Guidance for addressing inequities in overweight and obesity. http://www.euro.who.int/ data/assets/pdf file/0003/247638/obesity090514.pdf?ua= 1. Accessed September 52015.

Marshall, T., Simpson, S., Stevens, A. (2000). Toolkit for health care needs assessment in prisons. http://webarchive.nationalarchives.gov.uk/20130107105354/http://www.dh.gov.uk/prod consum dh/groups/dh digitalassets/@dh/@en/documents/digitalasset/dh 4034355.p df. Accessed August 302015 
Örs, M., Kalkan, I. (2016). Nutrional knowledge levels of adult prisoners in Amasya, Turkey. Advances in Social Sciences Research Journal (ASSRJ), 4(14):204-212.

Parmenter, K., Wardle, J. (1999). Development of a general nutrition knowledge questionnaire for adults. European Journal of Clinical Nutrition, 53: 298-308.

Steafleu, A., Staveren, V. W. A., Graaf, C. D., Burema, J. \& Hautvast, J. G. A. J. (1996). Nutrition knowledge and attitudes towards high-fat foods and low-fat alternatives in the generations of women. Europen Journal of Clinical Nutrition, 50(1): 33-41.

Sebelia, L., Greene, G. (2007). A Nutrition education program for prison offenders sentenced to home confinement. I Am Diet Assoc. 107:A95.

The Turkish republic ministry of justice. (2015). Tthe national legislation concerning the general directorate of prisons and detention houses. http://www.cte.adalet.gov.tr/menudekiler/mevzuat/protokol/protokol.asp. Accessed Marc 12015.

Türkiye Beslenme ve Sağlık Araştırması (TBSA). (2010). Saha uygulaması el kitabı. http://www.sagem.gov.tr/TBSA_Beslenme_Yayini.pdf. Accessed April 152015.

World Health Organization. (1986). Ottawa charter for health promotion. Health Promotion, 1:4, iii-v.

WHO. (2015a) Prison and health. http://www.euro.who.int/en/health-topics/healthdeterminants/prisons-and-health/publications/2014/prisons-and-health. Accessed August 20.

WHO. (2015b). Nutrition. http://www.euro.who.int/en/health-topics/healt determinants/prisons-and-health/activities/nutrition. Accessed August 28.

World Health Organization. (2003). Diet, nutrition and the prevention of chronic diseases. Report of a WHO study group. http://whqlibdoc.who.int/trs/WHO_TRS_916.pdf. Accessed August 252015. 